\title{
Prognostic value of epidermal growth factor receptor expression in cervical carcinoma
}

\author{
R J Hale, C H Buckley, W J Gullick, H Fox, J Williams, F L Wilcox
}

\begin{abstract}
Aims: To investigate the pattern of epidermal growth factor receptor expression and its prognostic value in the three main types of cervical carcinoma.

Methods: 62 cases of stage IB/IIA cervical carcinoma, all with a minimum of five years of follow up, were studied. Representative sections were stained for mucin to permit accurate tumour typing and a standard avidin-biotin immunoperoxidase technique using the polyclonal antibody $12 \mathrm{E}$ was used to demonstrate the presence of epidermal growth factor receptor.

Results: A proportion of all three tumour types expressed epidermal growth factor receptor, it being most common in squamous cell carcinomas (50\%). Overall, there was a correlation between epidermal growth factor expression and mortality. This was particularly obvious in the absence of lymph node metastases. When the individual tumour types were considered this association with prognosis was not demonstrable for squamous cell carcinomas or adenocarcinomas but was a very prominent feature of adenosquamous carcinomas.

Conclusions: Immunohistochemical demonstration of epidermal growth factor receptor expression may be useful in identifying those patients with a poor prognosis, particularly those with adenosquamous carcinomas which have not metastasised to the regional lymph nodes.
\end{abstract}

(F Clin Pathol 1993;46:149-153)

Department of

Reproductive

Pathology, St Mary's

Hospital, Manchester

R J Hale

C H Buckley

J Williams

H Fox

ICRF Oncology

Group, Hammersmith

Hospital, London

W J Gullick

Department of

Obstetrics and

Gynaecology, Royal

Victoria Hospital,

Blackpool

F L Wilcox

Correspondence to:

Dr R J Hale, Department of Reproductive Pathology, St

Mary's Hospital, Hathersage

Road Manchester M13 0JH

Accepted for publication

28 July 1992
The specific receptor for EGF (EGFR) was first purified from the A431 cell line which was derived from an epidermoid carcinoma of the vulva. It is a 170000 kilodalton trans- membrane glycoprotein encoded for by the $c$ $e r b \mathrm{~B}-1$ oncogene. It has three components, an extracellular domain capable of binding the ligand, a transmembrane portion, and an intracellular domain facing the cytoplasm. The receptor is capable of binding EGF, transforming growth factor (TGF) $\alpha,{ }^{3}$ amphiregulin, ${ }^{6}$ and heparin-binding EGF. The function of EGFR is to bind the mitogen EGF or TGF $\alpha$ and to transduce the signal across the cell membrane to the cytoplasm. The intracellular component exhibits tyrosine kinase activity and has binding sites for ATP. ${ }^{3}$ This results in the autophosphorylation of the EGFR and phosphorylation of several target proteins. ${ }^{89}$

EGFR is found on the surface of many cells, including normal and malignant cells of epidermal and mesenchymal origin but not in cells of the haemopoietic system. ${ }^{10-13}$ Different cell types express different numbers of cell surface EGF receptors, from none on lymphoid cells, to 250000 per cell on keratinocytes. ${ }^{11-14}$ This high level of receptors on keratinocytes reflects the important role EGF has in regulating the growth and differentiation of epidermal cells.

It has been suggested that overexpression of the EGFR is a common, if not constant, step in the malignant transformation of squamous cells, and that there is a close correlation between EGFR overexpression, EGF mRNA, and EGF gene amplification. ${ }^{5}$

EGF has been identified in breast carcino$\mathrm{ma}^{15-17}$ and has been shown to play an important part in regulating proliferation of both normal and neoplastic mammary epithelial cells. ${ }^{1518} 19$ It has been suggested that expression of EGFR in breast carcinoma is related to aggressive clinical behaviour, ${ }^{20-22}$ although this has not been demonstrated in other studies. ${ }^{2324}$ It is also known that EGFR and oestrogen receptor status in breast carcinomas are inversely correlated. ${ }^{1620212324}$

There is a need to identify markers of tumour aggressiveness in patients with cervical carcinoma to define groups with either a good prognosis (requiring no further treatment) or where the outcome is likely to be poor and where more intensive treatment might be beneficial.

Already identified as important prognostic factors in early stage cervical carcinoma (stage IB/IIA) are tumour volume, lymph node status, lymphatic permeation and pregnancy. Tumour type is not of confirmed value in predicting clinical outcome. The pattern of behaviour of the different tumour types is not, 
however, the same and the prognostic and biological importance of this requires further investigation. ${ }^{25}$

\section{Methods}

A total of 62 cases of early stage cervical carcinoma (all but one being stage IB) treated by Wertheim's hysterectomy at St Mary's Hospital, Manchester, form the basis of this study. None of the patients had received prior radiotherapy.

The different tumour types have different behavioural patterns ${ }^{25}$ and, therefore, the three main tumour types (squamous carcinoma, adenosquamous carcinoma, and adenocarcinoma) were equally represented.

Note was made of the presence or absence of lymph node metastases in each case. Follow up information of between 5 and 11 years' duration was available for all patients.

Tissue was formalin fixed, paraffin processed, and wax embedded. Using haematoxylin and eosin stained sections and periodic acid Schiff/alcian blue staining, with and without predigestion with diastase, the tumours were typed according to the criteria of Buckley and Fox. ${ }^{26}$

For immunohistochemical staining, sections were dewaxed and a standard indirect avidin-biotin immunoperoxidase technique was then applied. A rabbit polyclonal antibody $12 \mathrm{E}^{27}$ at a concentration of $4 \mu \mathrm{g} / \mathrm{ml}$ was used, the sections being incubated for 30 minutes at room temperature.

Human placental tissue was used as a positive control and negative controls involved the omission of the primary antibody.

Membrane staining was semiquantitatively graded on a four point scale according to the intensity of staining ( 0 negative; + weak; ++ moderate, and +++ strong).

The results were tabulated, put into numerical form, and analysed using Kendall's $\tau B$ and C (SPSS package for IBM compatible computers). A significant correlation between two parameters was taken at the $95 \%$ confidence limit, where $p<0.05$. Particular note was made of any correlation with clinical outcome, measured by death rate.

\section{Results}

The distribution of tumour types is shown in the table.

In most cases where ectocervical squamous epithelium was included positive membrane staining ( + ) was present in the basal and parabasal layers. Therefore, those tumours with grades 0 or + were regarded as negative

Distribution of tumour types and the number staining for EGFR in each group

\begin{tabular}{llll}
\hline & \multicolumn{2}{l}{ Staining for EGFR } & \\
\cline { 2 - 3 } Tumour type & Positive & Negative & Total \\
\hline Squamous carcinoma & $10(50 \%)$ & $10(50 \%)$ & 20 \\
Adenosquamous & $7(33 \%)$ & $14(66 \%)$ & 21 \\
Carcinoma & $4(19 \%)$ & $17(81 \%)$ & 21 \\
Adenocarcinoma & 41 & 41 & 62 \\
\hline
\end{tabular}

and those with grades ++ and +++ were deemed positive for overexpression of EGFR.

Positive staining was detected in 21 (34\%) cases. The numbers in each tumour type are shown in the table, positivity being seen most frequently in the squamous cell carcinomas $(p=0.019)$. Staining was variable between and within the tumours. In only three cases did more than $75 \%$ of the cells stain (fig 1). In the remainder positivity was restricted to scattered small groups of cells randomly distributed throughout the tumour. In squamous cell carcinomas, however, there was a tendency for staining to be localised to the peripheral cells of the infiltrating tongues of tumour (fig 2). The pattern of staining was not directly related to outcome, the important factor being the presence or absence of EGFR overexpression.

Only in adenocarcinomas was it possible to demonstrate any correlation between positive staining and the presence of lymph node metastases $(p=0.028)$.

Considering all three tumour types as a whole, there was a significant correlation between positive staining and death rate $(\mathrm{p}=$ 0.003 ). This was also true for patients without lymph node metastases $(p<0.001)$ but not for those with lymph node metastases (fig 3). However, this correlation seems to be due entirely to the influence of EGFR in adenosquamous carcinomas.

In patients with squamous cell carcinoma (fig 4) there was no correlation between positive staining and outcome, either overall or in those patients with lymph node metastases. However, a trend did exist between positive staining and outcome where nodal metastases were absent, although this failed to reach significance.

In the group of patients with adenosquamous carcinoma, there were significantly more deaths in patients with positive staining, both overall $(p=0.005)$ and in those lacking lymph node metastases $(p<0.001)$. When lymph node metastases were present no such correlation could be shown (fig 5).

In patients with adenocarcinoma no correlation could be demonstrated between staining pattern and clinical outcome, either overall or where nodal metastases were or were not present (fig 6). However, in this group of patients there was a very strong correlation between outcome and nodal status such that no deaths have occurred in those patients lacking nodal metastases (at the time of writing). Obviously this makes it very difficult to demonstrate any impact that EGFR expression may have on prognosis.

\section{Discussion}

Unlike breast carcinomas, where the expression of EGFR has been widely studied, ${ }^{15-24}$ EGFR expression in cervical carcinoma has been the subject of only a limited number of papers. It has been shown that squamous cell carcinomas of the cervix frequently express EGFR, ${ }^{1228-30}$ often at a high concentration. ${ }^{31}$ In one study, $41 \%$ of the cases showed over- 


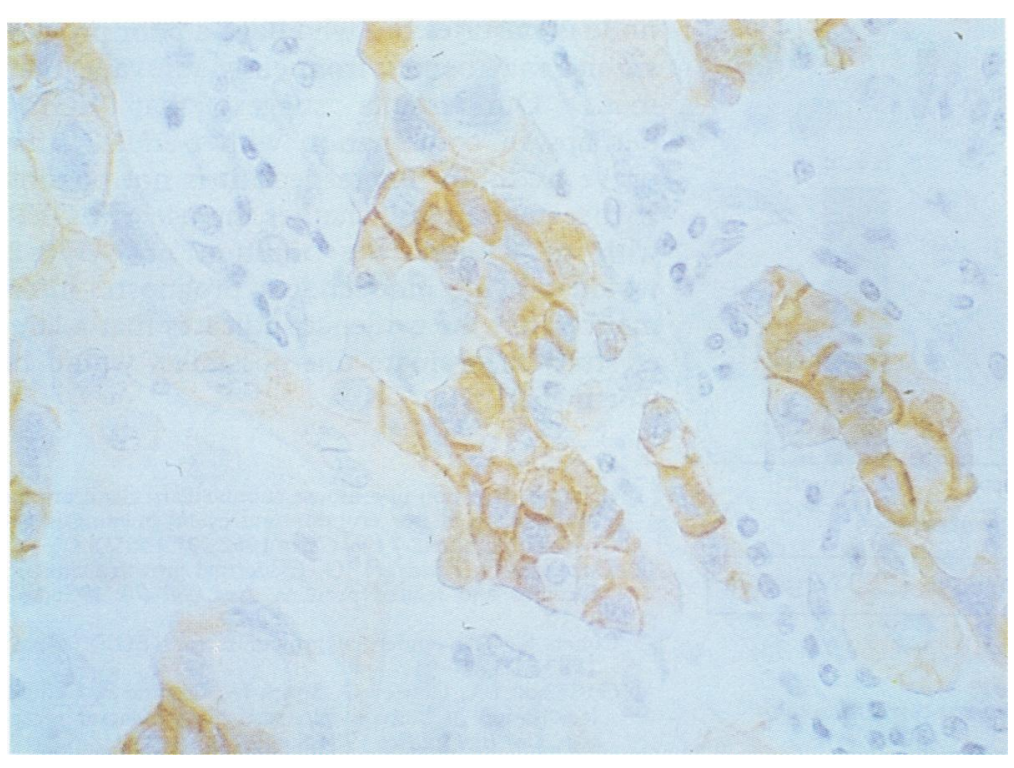

Figure 1 Prominent membrane staining in poorly differentiated adenocarcinoma indicating overexpression of EGFR.

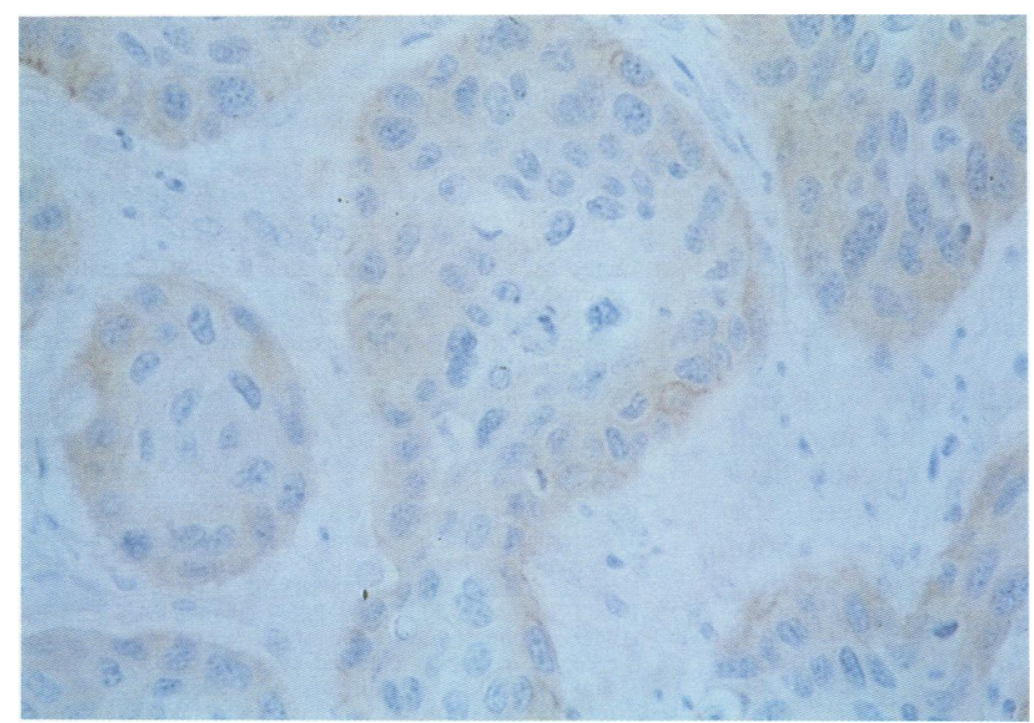

Figure 2 Squamous cell carcinoma showing patchy membrane staining with anti EGFR predominantly at the periphery of the tumour lobules.

expression of EGFR, ${ }^{31}$ a proportion similar to that found in the present study.

Overexpression of EGFR correlate with a worse prognosis according to Pfeiffer et al, ${ }^{32}$ who suggested that EGFR expression may be indicative of the biological aggressiveness of cervical squamous cell carcinomas. More recently, in a study in which clinical behaviour was measured by the presence or absence of lymph node metastases, no correlation could be identified between EGFR expression in squamous cell carcinomas of the cervix and nodal status. ${ }^{33}$ It was concluded that EGFR was, therefore, unlikely to be a useful prognostic marker.

To our knowledge, the present study is the first to investigate EGFR expression and its possible prognostic value in all three main types of cervical carcinoma.

We have shown that EGFR overexpression is most frequently seen in squamous carcinomas and least frequently in adenocarcinomas.

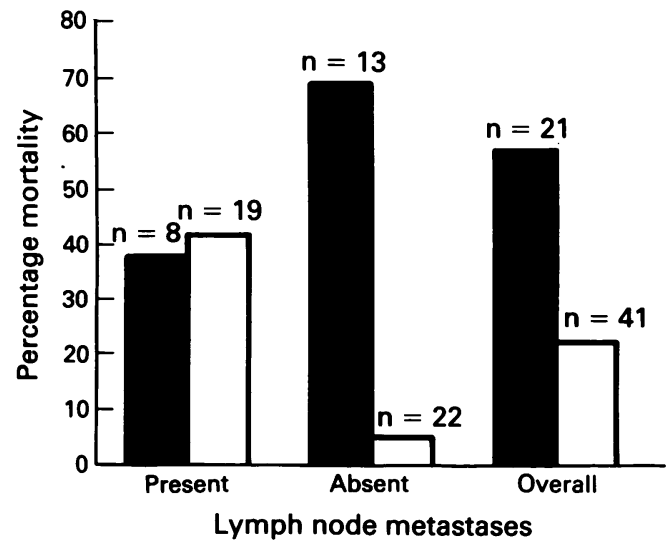

Staining pattern:

Positive $\square$ Negative

Figure 3 EGFR in cervical carcinoma: correlation with prognosis.

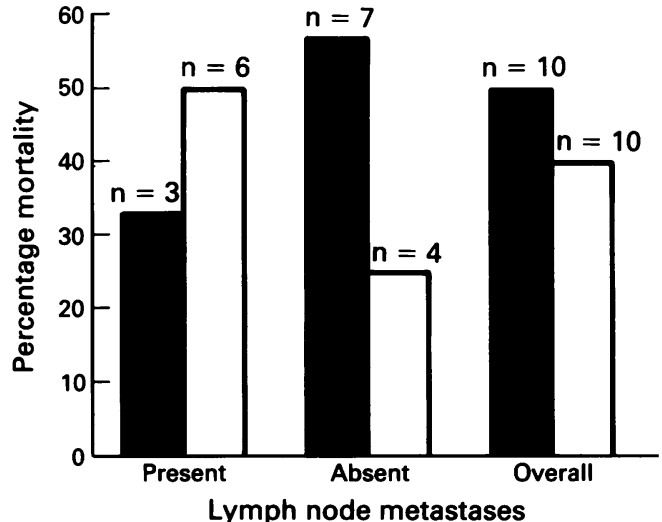

Staining pattern: $\square$ Positive $\square$ Negative

Figure 4 EGFR in squamous cell carcinoma: correlation with prognosis.

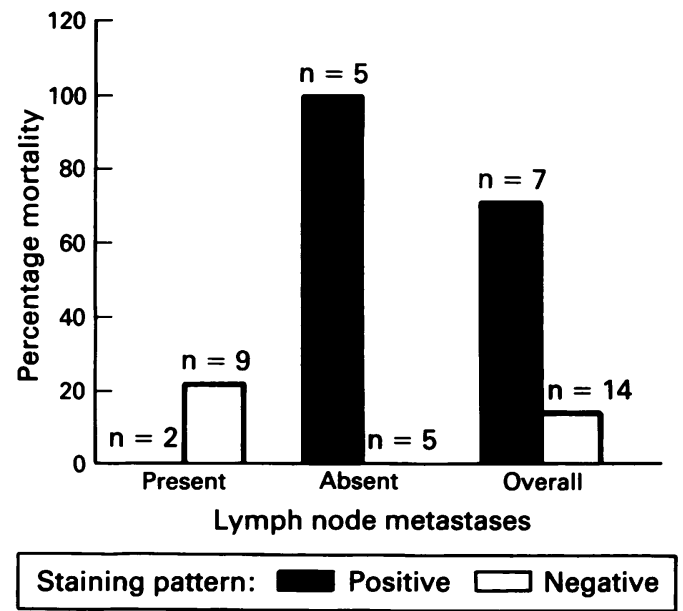

Figure 5 EGFR in adenosquamous carcinoma: correlation with prognosis.

Considering all three tumour types as a whole, like Hayashi and co-authors, ${ }^{33}$ no association could be shown between EGFR expression and nodal metastases. Only in adenocarcinomas was there a correlation 


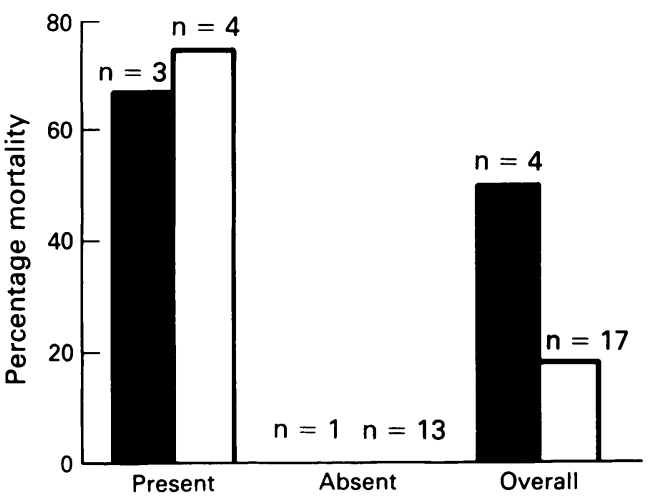

Lymph node metastases

Staining pattern: $\square$ Positive $\square$ Negative

Figure 6 EGFR in adenocarcinoma: correlation with prognosis.

adenocarcinomas was there a correlation between EGFR expression and the presence of lymph node metastases.

Overall, there was a significant correlation between EGFR expression and mortality, this being particularly prominent in those patients lacking lymph node metastases and absent in those with nodal metastases. However, this seems to have been almost entirely due to the influence of adenosquamous carcinomas where EGFR expression has a strong association with prognosis.

When the different tumour types were considered individually the only group in which any significant correlation with clinical behaviour could be demonstrated were the adenosquamous carcinomas. In those patients lacking nodal metastases all five whose tumours stained positively for EGFR died of disease while all five who were negative were alive and disease free. It is in this subgroup, particularly, that the evaluation EGFR expression may prove to be of clinical value. A similar pattern of behaviour was seen in the squamous carcinomas, but this failed to reach significance.

These results were compared with those obtained when c-erbB-2 expression was studied on the same group of patients. ${ }^{34}$ There was a close correlation between the results obtained with both antibodies $(p<0.001)$. This was particularly so in certain subgroups. Four of the six patients with squamous carcinoma and all five patients with adenosquamous carcinomas which stained positively with both antibodies and who lacked lymph node metastases have died of disease.

The identification of patients at high risk of recurrence and death from disease remains an important factor in patient management. In early stage cervical carcinoma one of the most important prognostic indicators is lymph node status. ${ }^{25}$ However, in absolute terms equal numbers of deaths from disease occur in patients with and without lymph node metastases. ${ }^{35}$ Therefore, it is important to try and identify those patients who lack lymph node metastases but who have a poor prognosis and may benefit from early adjuvant treatment. Our results suggest that EGFR, perhaps in combination with c-erbB-2, may prove useful in this respect. It is not possible at this stage to say whether the use of EGFR, with or without the addition of $c-e r b \mathrm{~B}-2$, would provide independent prognostic information, but the evidence indicates that a larger study to evaluate this possibility would be worthwhile.

1 Cohen S. Isolation of a mouse submaxillary gland protein accelerating incisor eruption and eyelid opening in the new-born animal. $\mathcal{f}$ Biol Chem 1962;237:1555-62.

2 Carpenter G, Zendegui JG. Epidermal growth factor, its receptor and related proteins. Exp Cell Res 1986;164: 1-10.

3 Cohen S. The epidermal growth factor (EGF). Cancer 1983;51:1787-91.

4 Gusterson BA, Cowley G, Smith JA, Ozanne B. Cellular localisation of human epidermal growth factor receptors. Cell Biol Int Rep 1984;8:649-58.

5 Ozanne B, Richards CS, Hendler F, Burns D, Gusterson B. Overexpression of the EGF receptor is a hallmark of B. Overexpression of the EGF receptor is a hallmark
squamous cell carcinomas. $\mathcal{F}$ Pathol 1986;149:9-14.

6 Shoyab M, Plowman GD, McDonald VL, Bradley JG, Todaro GJ. Structure and function of amphiregulin: a member of the epidermal growth factor family. Science 1989;243:1074-6.

7 Higashiyama S, Abraham JA, Miller J, Fiddes JC, Klagsbrun $M$. A heparin-binding growth factor secreted by macrophage-like cells that is related to EGF. Science 1991;251:936-9.

8 Cooper JA, Bowen-Pope DF, Raines E, Ross R, Hunter T. Similar effects of platelet-derived growth factor and epidermal growth factor on the phosphorylation of tyroepidermal growth factor on the phosphorylation
sine in cellular proteins. Cell 1982;31:263-73.

9 Ushiro M, Cohen S. Identification of phosphotyrosine as a product of epidermal growth-activated protein kinase in A431 cell membranes. $\mathcal{B}$ Biol Chem 1980;255:8363-5.

10 Carpenter G, Cohen S. Epidermal growth factor. Ann Rev Biochem 1979;48:193-216.

11 Cowley G, Smith JA, Gusterson B, Hendler F, Ozanne B. The amount of EGF receptor is elevated on squamous cell carcinoma. In: Cancer cells Vol 1. The transformed phenotype. New York: Cold Spring Harbor Laboratory, 1984:5-10.

12 Gullick WJ, Marsden JJ, Whittle N, Ward B, Bobrow L, Waterfield MD. Expression of epidermal growth factor receptors on human cervical, ovarian and vulval carcireceptors on human cervical, ovarian

13 Real FX, Rettig WJ, Chesa PG, Melamed MR, Old LJ, Mendelsohn J. Expression of epidermal growth factor receptor in human cultured cells and tissues: relationship to cell lineage and stage of differentiation. Cancer Res 1986;46:4726-32.

14 Ozanne B, Schum A, Richards CS, et al. Evidence for increased EGF receptor in epidermal malignancies. In: Cancer cells Vol III Growth factors and transformation. New York: Cold Spring Harbor Laboratory, 1985:41-9.

15 Imai Y, Leung CKH, Friesen HG, et al. Epidermal growth factor receptors and effect of epidermal growth factor on growth of human breast cancer cells in long factor on growth of human breast cancer cells
term tissue culture. Cancer Res 1982;42:4394-8.

16 Fitzpatrick SL, Brightwell J, Wittliff JL, Barrows GH, Schultz GS. Epidermal growth factor binding by breast tumour biopsies and relationship to oestrogen receptor and progestin receptor levels. Cancer Res 1984;44: 3448-53.

17 Perez R, Pascual M, Macias A, Lage A. Epidermal growth factor receptors in human breast cancer. Breast Cancer Res Treat 1984;4:189-93.

18 Fitzpatrick SL, LaChance MP, Schultz GS. Characterisation of epidermal growth factor receptor and action on human breast cancer cells in culture. Cancer Res on human breast

19 Tonelli QJ, Sorof S. Epidermal growth factor requirement for development of cultured mammary gland. Nature for development

20 Sainsbury JRC, Farndon JR, Needham GK, Malcolm AJ, Harris AL. Epidermal growth factor receptor status as a predictor of early recurrence of and death from breast cancer. Lancet 1987; i: 1398-402.

21 Wright C, Angus B, Napier J, et al. Prognostic factors in breast cancer: Immunohistochemical staining for SP1 and NCRC11 related to survival, tumour epidermal growth factor receptor and oestrogen receptor status. $\mathcal{F}$ Pathol 1987;153:325-31.

22 Nicholson S, Sainsbury JRC, Needham Gk, et al. Quantitiative assays of epidermal growth factor receptor in human breast cancer: cut-off points of clinical relevance. Int $f$ Cancer 1988;42:36-41.

23 Horne GM, Angus B, Wright C, et al. Relationship between oestrogen receptor, epidermal growth factor receptor, ERD5 and p24 oestrogen regulated protein in human breast cancer. $\mathcal{F}$ Pathol 1988;155:143-50. 
24 Wrba F, Reiner A, Ritzinger E, et al. Expression of epidermal growth factor receptors (EGFR) on breast carcinomas in relation to growth fractions, estrogen receptor mas in relation to growth fractions, estrogen receptor status and morphological criteria. An immun

25 Hale RJ, Wilcox FL, Buckley CH, Tindall VR, Ryder WDJ, Logue JP. Prognostic factors in uterine cervical carcinoma: a clinicopathological analysis. Int $f$ Gynecol Cancer 1991;1:19-23.

26 Buckley $\mathrm{CH}$, Fox $\mathrm{H}$. Carcinoma of the cervix. In: Anthony PP, MacSween RNM, eds. Recent Advances in Histopathology. 14. London: Churchill Livingstone, 1989:63-78.

27 Gullick WJ, Hughes CM, Mellon K, Neal DE, Lemoine NR. Immunohistochemical detection of the epidermal growth factor receptor in paraffin-embedded human tisgrowth factor receptor in parafin
sues. $\mathcal{f}$ Pathol 1991;164:285-9.

28 Battaglia F, Scambia G, Pacini PB, et al. Epidermal growth factor receptor expression in gynecological malignancies. Gynecol Obstet Invest 1989;27:42-4.

29 Bauknecht T, Kohler M, Janz I, Pfleiderer A. The occurence of epidermal growth factor receptors and the characterisation of EGF-like factors in human ovarian, endometrial, cervical and breast cancer. EGF receptors and factors in gynecological carcinomas. $\mathcal{F}$ Cancer Res
Clin Oncol 1989;115:193-9.

30 Berchuk A, Rodriguez G, Kamel A, Soper JT, ClarkePearson DL, Bast RC. Expression of epidermal growth factor receptor and HER-2/neu in normal and neoplasfactor receptor and HER-2/neu in normal and neoplas-
tic cervix vulva and vagina. Obstet Gynecol 1990;76: tic cervix

31 Kohler M, Janz I, Wintzer HO, Wagner E, Bauknecht T. The expression of EGF receptors, EGF-like factors and c-myc in ovarian and cervical carcinomas and their $1537-47$.

32 Pfeiffer D, Stellwag B, Pfeiffer A, Borlinghaus $\mathrm{P}$, Meier $W$, Scheidel P. Clinical implications of the epidermal growth factor receptor in squamous cell carcinoma of growth factor receptor in squamous cell carcinoma

33 the uterine cervix. Gynecol Oncol 1989;33:146-50. Hayashi Y, Hachisuga T, Iwasaka T, et al. Expression of
ras oncogene product and EGF receptor in cervical squamous cell carcinomas and its relationship to lymph node involvement. Gynecol Oncol 1991;40:147-51.

34 Hale RJ, Buckley CH, Fox H, Williams J. Prognostic value of c-erbB-2 protein expression in cervical carcinoma. $f$ Clin Pathol 1992;45:594-6.

35 Thomas GM, Dembo AJ. Is there a role for adjuvant pelvic radiotherapy after radical hysterectomy in early stage cervical cancer? Int $\mathcal{f}$ Gynecol Cancer 1991;1:1-8. 